\title{
Nurses' Experiences of Adverse Events Management at a Public Hospital, Gauteng Province
}

\author{
Elizabeth Malefu Nkosi ${ }^{1}$ \\ ${ }^{1}$ Department of Nursing, Faculty of Health Sciences, University of Johannesburg, Johannesburg, South Africa \\ Correspondence: Elizabeth Malefu Nkosi, Department of Nursing, Faculty of Health Sciences, Johannesburg, \\ Gauteng, South Africa. Tel: 27-11-559-6880. E-mail: elizabethn@uj.ac.za
}

Received: July 7, 2020 Accepted: September 25, 2020 Online Published: October 23, 2020

doi:10.5539/gjhs.v12n12p80 URL: https://doi.org/10.5539/gjhs.v12n12p80

\begin{abstract}
Background: Involvement in adverse events can be a traumatic experience that leaves the nurses with professional and personal distress. Some feel as though they have failed the patient doubting their nursing skills. While the effects of the event can be distinctively evident on the patient and hospital, the nurses in question often suffer in silence. The purpose of this study was to explore and describe the nurses' experiences of adverse events management at a public hospital, and to develop recommendations to address them.

Methods: A qualitative, phenomenological and contextual research design was used to explore and describe the nurse's experiences of management of adverse events at this public hospital in Gauteng, South Africa. A total of 18 professional nurses who met the inclusion criteria were purposively sampled. Data was collected by means of in-depth semi structured individual interviews and documented field notes. An audio tape recorder was used with the participants' consent to capture the participant's responses. Data was analyzed using Tesch's open coding method. Ethical principles to protect the rights of the participants were adhered to, and the criteria of trustworthiness was ensured.

Results: Findings of the study revealed that participants experienced negative management of adverse events. Three sub- themes emerged namely: inconsistency in the reporting and recording of adverse events, lack of managerial support and unplanned job rotation used as punishment following the events.

Conclusion: Involvement in adverse events has a negative impact on the nurses' wellbeing as well as patient care. Management should make efforts to promote awareness, implement positive management of adverse events, ensure consistency in the reporting and recording of adverse events including the provision of managerial support, and planned job rotation.
\end{abstract}

Keywords: adverse event, experiences, management, nurse

\section{Introduction}

Adverse events can cause physical and mental injury to patients and their families (Pyo, Han, \& Ock, 2018). However, the injury is not limited to the patient and families. The nurses in question can experience psychological distress including frustration, guilt, anger and fear; as well as physical symptoms such as fatigue and insomnia. Apart from these emotional and behavioural changes, these nurses were also reported to contemplate leaving the profession as they experienced decreased job satisfaction (Scott, Hirschinger, Cox, McCoig, Brandt, \& Hall, 2009). Experiencing an adverse event can have a lasting effect on every nurse in question, irrespective of their age, years of experience, or sex (Seys, Wu, Van Gerven, Vleugels, Euwema, \& Panella, 2013). These emotions have an impact on both their professional and personal lives. As a result, the nurses need time to recover from adverse events, however recovery relies on the extent to which hospital management support them.

Extensive efforts were made in hospital settings to manage the adverse events, with many preventive strategies implemented to help detect and eliminate their frequency and improve patient safety; however, the experiences of the nurse in question regarding the management thereof were overlooked and not discussed. According to Swift, (2013), the events are inevitable because human beings are involved in providing care. Furthermore, the nurse will always be blamed for unintentionally inflicting potential or actual harm while caring for the patients.

It has been reported that after several hospitals implemented standardised procedures to investigate these events, the staff became aware of system defects related to reporting and recording. However, hospitals failed to recognise 
these defects and impact of events on the nurses in question who suffered emotional distress (Edrees et al., 2016). Some studies reported that after details of events are forwarded to managers, and the internal reporting system; a debriefing session was conducted with nurses in question and investigations followed. However, they recognised a gap in the ability of the hospitals to provide reliable and timely intervention and support. Subsequently, leaders in patient safety, risk management and clinical departments began meeting to discuss the extent and importance of the challenges, existing infrastructure to support the nurses in question. The renewed focus was on the nurses' experiences and in developing strategies to improve the internal reporting and recording systems (Edrees, Connor, Paine, Norvell, Taylor, \& Wu, 2016).

In coping with the adverse event management, nurses faced the experience by thinking it over and communicating the fears and concerns to colleagues or friends. They learnt to live with what has happened and finally regained control by starting the journey to recovery in isolation. However, because the recovery process can sometimes last for weeks or months, those nurses in question have an increased risk to developing symptoms of post-traumatic stress disorder (PTSD) (de Boer et al., 2011).

\subsection{Problem Statement}

Published studies have indicated that hospitals support to nurses in question following adverse events was inadequate (Ullstrom et al., 2014). A range of intervention programs to support was acknowledged and described, including different methods and tools to support (Ferris et al., 2016). However, few hospitals have assessed the need for, availability of and efficiency of these support services. According to Edrees and $\mathrm{Wu}$ (2017), the majority of patient safety representatives who participated in their study strongly agreed that hospitals should consider offering support programmes, even though many of them do not have current evidence of effective and reliable programmes.

Regardless of the importance and high prevalence of studies on nurses suffering following adverse event, few hospitals have developed processes and procedures for supporting them. Literature indicates that there is scanty research on the specific support that nurses need from their hospitals, and the extent to which those needs are met (Ullstrom et al., 2014). Other hospitals have reported existing support for the involved nurses, however scientific evidence on the caliber of support expected and needed was inadequate (Leferink, Bos, Heringa, van Rensen, \& Zwart, 2018). The nurses in question need to be able to talk about the adverse event, receive empathy, and experience a sense of being supported by management. A study conducted by Mira, Carrillo, Guilabert, Lorenzo, Perez-Perez, Silvestre, Ferrus, and Spanish Second Victim Research Team (2017), reported that after an occurrence of adverse event, most of the nurses do not know what to do, or who to turn to for guidance.

Some nurses doubt the attitude, empathy, or respect they will receive from management following their involvement. In this study, the researcher could not find any reports related to the nurses' experiences of adverse events management at this specific public hospital. The study aims to explore and describe these experiences, assist towards the development of recommendations for management to provide support, and promote quality nursing care. In view of the background and problem statement, the researcher desired to explore the research question below: What are the nurses' experiences of adverse event management at the public hospital?

\subsection{Research Purpose}

The study aims to explore and describe the nurse's experiences of adverse events management in order to develop recommendations to that effect.

\subsection{Definition of Key Concepts}

1.3.1 Adverse events are described as any event that occurs during a patient's stay in hospital, which results in unexpected or unintentional physical harm, injury, disease, or disability (Muller et al., 2011:487). In this study, nurses who were involved in adverse events were the focus of the study.

1.3.2 Experience is the knowledge that comes from being personally involved in a situation, or circumstances, or an event. (Burns \& Grove, 2009:9). In this study, the experiences of nurses involved in adverse events were the focus of the study.

1.3.3. Management refers to a process of exploring, scrutinizing, investigating and evaluating the circumstances related to the occurrence of an adverse event (Muller, Bezuidenhout, \& Jooste, 2011).

1.3.4 A 'nurse' is defined as a person who is registered or enrolled with the SANC in a category under section 31(1), in order to practice nursing or midwifery, based on the completion of a recognised education and training programme to nurture, assist, and treat patients; a person trained to care for the sick or infirm (RSA, 2005:6). In this study, 'nurses' refer to registered nurses involved in adverse events at this public hospital were the focus. 


\section{Materials and Methods}

\subsection{Design}

This study used a qualitative, exploratory, descriptive, and contextual design. The researcher sought to explore, as well as interpret the meaning of the richness and complexity of the lived nurses' experiences of adverse events management. Qualitative research allows the researcher the opportunity to describe the experiences and circumstances from the participants' perspective. This is in order to gain in-depth understanding, including ability to immerse self in the data and literature relating to the nurses' experiences (Polit \& Beck, 2018).

\subsection{Setting}

This study was conducted at a regional academic hospital, situated approximately 10 kilometres from Johannesburg Central Business District (CBD), along a busy taxi route that connects Johannesburg to Roodepoort, Westbury, and Randburg. A residential area is on one side of the route, with one of the Gauteng nursing colleges situated towards the back entrance of the hospital, and a University is located on the one side. It is a 460-bedded hospital, rendering rehabilitative and curative services. It also serves as a referral point for General Practitioners and Primary Health Care Centres around Gauteng, Soweto, and surrounding areas.

\subsection{Population and Sampling Technique}

A population is a particular group of people representing the focus of the study and met the sampling criteria for inclusion in the study (Gray, Grove, \& Burns, 2017). In this study, the population consisted of registered nurses who were permanently employed at the hospital. Purposive sampling technique was used to select the nurses who had been involved in adverse events and who were willing to share their experiences towards the phenomenon. Purposive sampling refers to the researcher's selected sampling of certain participants that will be included in the study, as they provided more information regarding the phenomenon (Polit \& Beck, 2018). The inclusion criteria were nurses, who were willing and consented to partake in the study, employed for more than two years and were involved in an adverse event in the past three years. The exclusion criteria were all nurses who were on part time basis and were not involved in adverse events in the past three years.

\subsection{Recruitment Process}

Following the approval and ethical clearance from the relevant structures, the researcher proceeded with the recruitment process as follows. The researcher visited the hospital and following the meeting and permission by the hospital manager, conducted a ten minutes Power Point presentation after one of the hospital feedback gatherings. Subsequently a question and answer briefing session were held with the Nursing Services Manager and other Operational Managers in attendance giving an overview of the proposed research study. An alternate date was scheduled and confirmed with the NSM in which similar content was going to be presented to all available hospital registered nurses immediately after one of their monthly meetings. The registered nursing staff were given an overview and to build rapport between them and the researcher in a dedicated venue and time. Any questions were answered and clarified by the researcher. Study information pamphlets were distributed among those who attended to read later at their own pace and be familiar with the proposed study. Included were the researcher's contact details should the interested persons have unanswered questions or needed clarity.

Registered nurses were recruited if they met the following inclusion criteria: Permanently employed for over two years period, because those newly employed within their first year, they have to serve probation for six months then are rotated to various departments till settled in the hospital routine, involvement in an adverse event in your career and willingness to share your experience. The study excluded: those nurses employed on a contract basis, student nurses and other categories of staff, agency staff and those who never experienced or were never involved in an adverse event in their career. The participants who were willing to partake in the study and to be interviewed were given consent forms for partaking and to be audio tape-recorded. The participants in view of their work schedules and family commitments chose the venue, date, and time.

\subsection{Interviews}

Data were collected by the researcher using in depth semi-structured individual interviews, conducted in English between May and November 2014. The duration of each interview was about 45 to 60 minutes, conducted in the hospital boardroom, dining hall and nurse's rest rooms. The interviews permitted flexibility of participant's availability and time, while preventing interruptions to the hospital routine. The main question, which steered the semi-structured interviews, was: 'What were your experiences of adverse events management at this public hospital?' The researcher used communication clarification techniques such as summarizing, probing, paraphrasing, listening, and focusing to ensure the exploration of the nurses' experiences (De Vos et al., 2011). The 
interviews were audio tape recorded with the permission of the participants for depicting and transcription of data. The researcher documented field notes during the interviews in which pauses, and numerous emotional expressions were documented to transcribe the themes.

The collected data were transcribed verbatim immediately after each interview and as soon as data collection was completed (De Vos et al., 2011). Data saturation was reached after the $18^{\text {th }}$ participant, in which no new information emerged (Creswell \& Creswell, 2018)

\subsection{Data Analysis}

To analyze data, the researcher utilized Tesch's open coding method of data analysis as described in Creswell (2012), as it permits accuracy in the analysis of qualitative data by use of the eight logical steps. Data was analyzed and the researcher and the qualitative research independent coder confirmed findings. A consensus meeting on identified themes was held between the researcher and the independent coder (Creswell, 2013). Follow-up interviews were done to verify the accuracy of the identified themes. Verbatim transcripts and audio recordings were analyzed, and the following themes transpired. See Table 2.

\subsection{Trustworthiness}

The researcher adhered to Lincoln and Guba's four strategies of establishing trustworthiness of a qualitative study, which are credibility, transferability, dependability and confirmability (1985). Credibility was ensured by spending adequate time with the involved nurses and triangulation by taking field notes. Member checking was achieved by means of follow up interviews with some of the participants to verify collected data. Transferability was achieved by purposive sampling, description of the research context and methodology. Dependability was ensured by provision of the research methodology. For conducting an inquiry audit, the audio tape-recorded interviews, transcriptions and participants' consent forms were securely locked away. Confirmability of the study was enhanced by the use of an independent coder and a confirmability audit.

\subsection{Ethical Considerations}

Ethical approval to conduct the study was obtained from the Research Ethics Committee at the University of Johannesburg (AEC01-01-2014) where the researcher is employed. The specific hospital where the study was conducted also provided an ethical clearance. Guiding the study was the following ethical principles: the principle of respect for persons, justice and beneficence as illustrated by Dhai and McQuoid- Mason (2014).

The purpose, objectives and study methods were explained to the participants. Subsequently, informed consent to voluntarily participate in the study, and consent to the use of an audio tape recorder were obtained from all participants. The participants were informed that they could withdraw from the study at any given time without penalties. Confidentiality was adhered to through the safekeeping of interviews under lock and key and ensuring restricted access to the data. Pseudonyms, which were created by the participants, were used to ensure anonymity and for protection of their privacy.

\section{Results}

\subsection{Participants Demographics}

Table 1. Participants' demographics

\begin{tabular}{ll}
\hline PARTICIPANT'S DEMOGRAPHICS & \\
\hline Age Range & $35-55$ Years \\
Gender & Females x 11, Males x 7 \\
Number of Participants & 18 \\
Ethnicity & African x 12, Whites x 4, Asians x 2. \\
\hline
\end{tabular}

Themes emerging from the study revealed that the participants experienced inconsistency in the reporting and recording of adverse events, lack of managerial support and unplanned job rotation that was used as punishment by management. See Table 2 below: 
Table 2. Themes and sub-themes generated

\begin{tabular}{lll}
\hline THEMES & SUB THEMES \\
\hline & $\bullet$ & Anger and loneliness \\
Inconsistency in the reporting and recording of adverse & $\bullet$ & Harassment and Rejection \\
events & $\bullet$ & Lack of guidance \\
& $\bullet$ & Confusion \\
\hline & $\bullet$ & Embarrassment \\
Lack of managerial support & $\bullet$ & Undermined and disrespected \\
& $\bullet$ & Humiliated Sadness and frustration \\
& $\bullet$ & Suffocation \\
& $\bullet$ & Speechlessness, worthlessness, desperation \\
& $\bullet$ & Pressure and frustration \\
\hline & $\bullet$ & Anger \\
\hline & $\bullet$ & Punished, rejection, exclusion \\
& $\bullet$ & Sadness \\
& $\bullet$ & Frustration \\
& $\bullet$ & Sickness \\
& $\bullet$ & Rage, Anger \\
\hline
\end{tabular}

\section{Theme 1: Inconsistency in the reporting and recording of adverse events}

The study revealed that the participants experienced the process of reporting the adverse event as inconsistent. The nurses were not clear on the process to be followed when reporting and recording the adverse events in this hospital Some said they received insufficient information and there was no guidance in that regard. This uncertainty resulted in confusion and frustration among the nurses. They also uttered that there were no properly formulated policies nor guidelines to indicate the sequence, and no one was available at the time to ask for clarity, which made it difficult for the reporting to take place. This participant experienced a sense of harassment and rejection from the OM, which resulted in feelings of anger as, stated below:

"I called my OM on her cell phone as she was out of office at the time.

OM: Why you are telling me this, have you told the Quality person, are the forms completed and sent out"

"And she yelled at me, not giving me chance even to find out why I called her and what I needed from her. I could hardly ask which forms must be completed as she had chopped my head off already. She cut the call abruptly and left me holding the receiver like a lost sheep..." (Sounding angry) (Participant 3 )

The participant experienced loneliness and lack of guidance during the time of need. This is what she said:

"At this crucial time no one is there guiding you on what to do precisely; especially because even your best mate does not want to be associated with you. My tea buddy who was always having her meal breaks with me for ward coverage was on her way to the dining room and I walked towards her to confirm if the sequence was fine, she just gave me that blank look and walked away.... I was shattered and felt lost big time.... tears were starting to fill my eyes... it was really difficult for me”. (Frowning, looking down). (Participant 8)

It became evident that participants were uncertain of the process to be followed to report and record the adverse event. They verbalized that they also felt confused and frustrated by the lack of knowledge and clarity on the process. One participant seems to be experiencing confusion from the multiple pages and forms that had to be completed within a short space of time, also without guidance:

"This whole process is disorganized, and no one seems to know what goes where, worse if there is hardly anyone to ask. There are too many pages and confusing forms, why can't they have one simple form in plain English? Patient Falls, medication error and bedsores all different books and yet the orientation was just focusing on one book, now what". For instance, let me tell you; blood ordering book has one form, whether plasma, platelets or fresh blood, why can't we have the same for incidents?" (Sounding concerned) (Participant 2) 
A participant verbalised loneliness, frustration and sadness due to lack of assistance and guidance from the OM as indicated below:

"I was alone in writing that statement, and I just had to report and record. After writing three pages, I tore them and started all over again with no one to turn to for assistance or guidance. I cried and not even my OM was around to comfort me. She kept away on purpose. I started to wonder if she even cared about what was going on .... What type of a place is this, really" (Sounding frustrated and sad)? (Participant 5)

During the interviews, participants affirmed that the reporting process was hurried as management wanted to complete the investigation and proceed to the review, and the delay in reporting resulted in being shouted at and called names. This made them feel like they were not valued. This participant uttered feelings of worthlessness, desperation, and anger as she was being shouted at and called names, which further made her to feel discouraged:

ZONE MATRON: "you are a hazard; how can you kill a healthy patient like that? You have twelve years of service for nothing; I wonder what you learnt all those years".

"I felt worthless; OH my word.... I do not like working here; you are called a hazardous nurse simply because of one incident, forgetting the good number of years I gave of service? That made me very angry seriously. These people are insensitive and heartless... (Sounding desperate) (Participant 11)

One participant experienced harassment and being undermined by the secretary who was yelling at him.

"I have worked at the previous hospital for seven years and not once did someone call me that, how come supervisors are so mean in this place?

Quality office secretary: "are the forms on the way, hurry ... hurry ... I need to capture that information on the system and forward to the CEO before I leave dear colleague”. She yelled over the phone.

"Imagine a whole senior nurse like me being questioned by a general worker where the forms are. You are treated like dirt here; I do not belong here, maybe I should start looking for another job elsewhere, where I will be valued and not treated this way" (Sounding sad) (Participant 9).

\section{Theme 2: Lack of managerial support}

The study also revealed that following the adverse event, nurses in question were blamed and shamed. There was no empathy displayed by their supervisors. Some reported that this disrespect confirmed their experience of lack of support from management. They were addressed in the presence of the visitors, other stakeholders and colleagues. A participant experienced trauma from both the adverse event involvement and the Quality Manager, which left him with a feeling of humiliation, frustration and embarrassment:

"I had just completed the phone call to the Quality Manager when she stormed to the ward in full view of the visitors and colleagues.

Quality Manager: "why didn't you do this ... why didn't you do that... you were negligent... what were you thinking?

"I mean, I am still traumatized and very emotional, shaking from the ordeal, and that is all she could say to me? What a cheek and she walked away into the office leaving me standing there" (Sounding annoyed) (Participant 3 )

This participant experienced embarrassment, being undermined and disrespected, humiliated and frustrated.

"The OM arrived and after reading my statement furious.

OM: "what English have you written now here, which year did you pass matric?"

"All this was said aloud during visiting time in front of junior colleagues, student nurse, visitors and patients. I was so embarrassed and could not believe it; I froze and could not answer this person. I felt miserable and for someone so senior to treat me like that...I felt like dirt. I wanted a hole to hide myself.... how can someone just condemn and humiliate you when you need their shoulder to cry on?" (Sounding frustrated) (Participant 13)

Some participants indicated that management seldom visited wards unless an adverse event had occurred. On arrival staff was quick to be blamed following adverse events involvement, and they (management) addressed them in a manner that belittled them. A participant experienced suffocation, speechlessness, being annoyed and belittled, as stated:

"The matron left me shaking, my mouth was hanging, and I could not believe the words came out of her mouth. It's like I left my home with the intention of hurting a patient. It felt like the world was closing down on me, I was suffocating and speechless" (Sounding annoyed) (Participant 17). 
Another experienced intimidation, anger and being disrespected:

: “.... When something has happened in the wards, management is quick to come asking too many questions? The Deputy spoke about me getting a warning for what... I don't even know why I am getting a warning. "I can't be all over the entire ward as if I am working alone" (Sounding angry) (Participant 15). She just shouted at me:

DEPUTY MATRON: "You are not focusing on your work, what were you thinking, you were supposed to do this and that. You deserve a final warning for this. Where were the other nurses, what were they doing?"

During the interviews, it emerged that the participants were feeling stressed, angry and bottled up their emotions, because of lack of respect displayed by management when confronted with the adverse event report. This participant experienced pressure, disrespect and frustration:

"... I was so bottled up and ready to explode.... where is the confidentiality and respect in all this? Does it mean because of the incident I can be treated like this...? Not at all" (Sounding frustrated) (Participant 10)

\section{Theme 3: Unplanned job rotation used as punishment}

The findings also revealed that following adverse events, they (participants) observed colleagues being moved from one ward to another without prior planning. They believed that this was management's efforts to protect and uphold the hospital image. This led them to behave negatively towards the OM in the ward where they were placed. This participant experienced sickness, confusion and rage:

"I received a call from the OM while day off informing me about my confirmed relocation to another ward with immediate effect".

OM: "Nurse J, remember that tomorrow when you return on duty you have to report to the medical ward, just till the investigation period is over, you need to be away from the ward for the dust to settle".

"As if this ward was nice. When I asked the reason for my relocation, she just hung up before I could ask further questions... I was so sick after that phone call .... I went immediately to my physician, who advised me to write a grievance and contact HR on my return. I was trying to come to terms with this sudden change of my routine. My day off was spoiled ... I mean I had bonded with my colleagues and patients, so now, because of my incident I had to be treated and moved like that...no way. (Sounding furious) (Participant 1)

During the interview, it became evident that some wards in the hospital were named "concentration camps". Once you are moved there, all the staff knew you were being punished following your actions. However, adverse event movements were believed to be rarely associated with this practice. In contrast, this participant was moved to one of the concentration camps and upon enquiry, she overheard that the adverse event she was involved in earlier caused her unplanned move. She became angry and unhappy due to lack of management communication with her on the matter. She experienced rejection, loneliness, exclusion and anger; and she felt punished, as stated below:

"I returned refreshed from my two weeks of annual leave only to be told upon arrival about the move".

OM: "Nurse P you will be moved to Ward A, due to your recent actions".

"I could not believe it, upon asking the OM she looked away and went quickly into the office. I was crying as I entered that ward and the atmosphere was very tense. I approached the Charge person to enquire about my sudden move and she looked away, ignoring me. During my tea break I wrote a letter to HR and informed them that I wanted to resign immediately, but because I just returned from annual leave, I was told that I had to serve a months' notice. This move was a bomb, no planning, no communication, nor preparation. I had to deal with it. How does this hospital operate seriously, I have mixed feelings right now..." (Sounding angry) (Participant 6)?

\section{Discussion}

The objective of this study was to explore and describe the nurses' experiences of adverse events management. The findings confirmed that the participants negatively experienced the adverse events management, and this left them angry.

In addition, the inconsistencies in the reporting and recording of adverse events left the participants feeling lonely, confused and rejected. When a person is allocated a task, they require guidance and clarity on how the task should be accomplished. The lack of guidance left them feeling angry and furious, which further exposed them to other adverse events occurring because they were not focused as supported by Ullstrom et al., (2014). Anger and frustration resulted from the lack of guidance and lack of clarity as revealed by the participants. They also reported experiences of harassment and rejection as none of the other staff wanted to be associated with them during this time. They felt worthless and desperate to find someone to assist them complete and report the event as required within the stipulated time frame. This couldn't be accomplished timeously due to multiple and complex forms. The 
experiences above affected them adversely.

These findings collaborate with Mira et al., (2017), that the complexity, inconsistency in the methodology of reporting an adverse event often left the nurses in question confused, angry and frustrated. Rafter, Hickey, Condell, Conroy, O'Connor, Vaughan and Williams (2015), also supported that in view of the above, measures should be implemented to ensure that the reporting and recording be simplified to prevent the confusion and enable a smooth and prompt process. Open platforms for discussions and participative investigation processes should benefit both the hospital and nurses in question, in view of lack of clarity on the process to follow. Evidence of rejection and lack of guidance towards nurses with colleagues distancing themselves for fear of being implicated should be investigated and discontinued (Swift, 2013; Ullstrom et al., 2014; \& Rafter et al., 2015).

Other participants felt strongly that guidelines should be developed and implemented for nurses in question following adverse events. It is imperative that a simple, universal and well-understood reporting tool be developed and implemented in the public hospitals in Gauteng. The complex, multiple forms in place should be discontinued to prevent the confusion, frustration and loneliness experienced. These can be replaced with simple, user-friendly documents that will accelerate the process without all the above-mentioned experiences. Categories should be uniform in all provinces. Regular in-service education to both new and regular staff can remind everyone on the process to be followed.

Lack of managerial support subjected the participants to embarrassment, being undermined by colleagues, humiliation, sadness and frustration. The workplace is where most of the professionals spend most part of the day, and to experience lack of support was verbalized as the worst trauma they could imagine. Immediately following the event, the nurses in question were assigned individual responsibilities irrespective of how they felt. Some experienced anger, pressure, suffocation, speechlessness hence they suffered in silence. This finding was supported by Ulstrom et al., (2014; Swift, 2013, Jones \& Treiber, 2012). Other nurses in question uttered experiences of intimidation and being disrespected. It appears as though management was quick to accuse, blame and shame the nurses such that they felt like being thrown under a moving bus due to lack of much needed support. The experiences affected them negatively. Previous studies provided findings, which were consistent with this study. Following the above, it was evident that immediate and continuous management support was lacking following adverse events. Instead, the nurses in question were left experiencing guilt feelings, anger, emotional and psychological distress (Grissinger, 2012; Sobekwa \& Arunachallam, 2015; Mohsenpour, Abbaszadeh, Shaboulagni, \& Khankeh, 2016).

Some participants felt that the negative attitude from management aggravated their emotional burden following adverse event involvement. To publicly criticize, blame and shame the nurse worsens the stress and delays the healing and recovery process. When a person experiences support from their immediate supervisor, it instils a sense of belonging and prevents experiences of frustration, fear and anxiety pending the punishment that usually follows the review of events. This finding is supported by Ullstrom et al., (2014; Lewis, Baernholdt, \& Hamric, 2013; Clark, 2014), that the insensitive reaction, attitude and nature of approach by management should be replaced by sympathetic, sensitive and caring reaction, where the personal and professional reassurance is afforded the nurse in order to reduce and prevent anger and frustration. Appropriate support and assistance can alleviate the distress experienced by the nurses in question.

It emerged that hospitals had a culture of conducting the Incident Reviews in order to further humiliate, blame and punish the nurses, by interrogating and stigmatizing them. Vanhaecht et al., (2019), reported that the approach during the reviews were insufficiently researched, making this process challenging for management. A properly formulated, review mechanism should be implemented starting from a no humiliation, blame-free, non-punitive and just culture. Participants felt strongly that management should not abandon them during this difficult time. Steps to adequately offer support were needed to improve quality patient care (Jones \& Treiber, 2012; Pelt \& Faldmo, 2012). Suggestions were made that management should refrain from interrogating or questioning anyone in the presence of colleagues, patient and visitors, instead to find, and create a discreet and respected space to address them.

According to Ngako, Rensburg, and Mataboge (2012:7), Sodeify et al., (2013), and Kirby (2014), the nurses in question should receive immediate emotional support from management following the adverse events, in order to eradicate guilt feelings and the intense emotional distress encountered. Support is one of the key roles for nurses they have to first perceive and experience it themselves before they can play this role or express it to the patients in their care. Cabilan and Kynoch (2015:64) agreed that management support was crucial for the emotional recovery of the nurses. Formal and comprehensive support networks and coping mechanisms should thus be developed and implemented, including structures to close the loop and learn from the adverse events (Swift, 2013; Edrees \& 
Federico, 2015; Abdi, Delgoshaei, Ravaghi, Abbasi, \& Heyrani, 2013).

Some of the participants experienced sickness, confusion, being furious, rejection, felt punished, excluded and anger following exposure to unplanned job rotation. While others felt strongly that job rotation was necessary to diversify activities in the workplace, some suggested that it should be implemented after consultation and agreement between involved parties. However, in this study it emerged that staff were abruptly rotated to other departments following adverse events. The nurses in question subsequently experienced rejection and were eventually sick. A participant had to be booked off from work in order to process the abrupt unplanned rotation to another department, which she was not familiar with. Other findings collaborate with Mohan and Gomathi, (2015), that planned job rotation has positive advantages for both the hospital and individuals alike which included; the promotion of staff experience, enhanced wellbeing and attitude, prevention of staff exhaustion from executing repetitive tasks variety, and usefulness as a tool for measuring the effectiveness of the management style in place (Partanen, 2014).

Because of the unplanned rotation, the participants were negatively affected, uttering experiences of demotivation and tension, depriving them of the necessary skills for future promotions and intensified work designs. This resulted in job alienation and turnover. Partanen (2014:30) believes that suitable planning for the implementation of job rotation can reduce turnover and unhappiness, resulting in positive workplace environments. For this reason, it should occur in a planned manner within hospitals.

\section{Conclusion}

Nurses often experience substantial emotional distress after adverse events. Feelings of shame, guilt, loss of empathy, isolation, anger, lack of confidence, and depression are all probable responses that affect them adversely. Physical responses such as elevated blood pressure, muscle tension, rapid heart rate, and sleeplessness occur. The major factors identified in this study were inconsistency in the reporting and recording of adverse events, lack of managerial support and unplanned job rotation used as punishment following adverse events. Immediate support in the outcome of an adverse event is crucial. It is imperative that efforts to help the nurses to cope be offered by management immediately after the event as well as intermittently thereafter. It is recommended that hospitals define standards of compassionate support for nurses dealing with the emotional repercussions of adverse events, in order to improve outcomes. The study highlighted that additional studies are needed in order that management can have a better understanding of the nurses' emotional and psychological needs following involvement in adverse events.

\section{Limitations and Strengths}

The study explored and described the nurses' experiences of adverse events management at a public hospital in Gauteng. However, the study was conducted in one public hospital and thus the findings cannot be generalized to other hospitals. The strength of this study is that management is now aware of how the nurses experienced the adverse events management at this hospital.

\section{Author Contribution}

The author designed, conceptualized, collected, analyzed, interpreted the results and drafted the manuscript.

\section{Competing Interests Statement}

The author declares that there are no competing nor potential conflicts of interest.

\section{References}

Abdi, Z., Delgoshaei, B., Ravaghi, H., Abbasi, M., \& Heyrani, A. (2015). The culture of patient safety in an Iranian intensive care unit. Journal of nursing management, 23(3), 333-345.

Burns, N., \& Grove, S. K. (2009). The Practice of Nursing Research. Appraisal, Synthesis and Generation of Evidence $\left(6^{\text {th }}\right.$ ed.). Philadelphia: Saunders Elsevier.

Cabilan, C. J., \& Kynoch, K. (2017). Experiences of and support for nurses as second victims of adverse nursing errors: a qualitative systematic review. JBI Database of Systematic Reviews and Implementation Reports, 15(9), 2333-2364.

Clark, J. (2014). Healing our own: The Second Victim Phenomenon and a New Approach to Quality Care. Retrieved from https://www.carilionclinic.org/sites/...Healing\%20Our\%25Own\%20Presentation.pdf

Creswell, J. W., \& Creswell, J. D. (2018). Research design: Qualitative, quantitative, \& mixed methods approaches (5th ed.). London: Sage. 
Creswell, J. W. (2017). Research design. Qualitative, quantitative and mixed methods approaches (4th ed.). Thousand Oakes, California. Sage Publications.

Creswell, J. W. (2013). Qualitative Inquiry and Research Design. Choosing among five approaches (3rd ed.). London: Sage.

De Boer, J., Strydom, H., Fouche, G. B., \& Delport, C. S. L. (2014). Critical incidents among intensive care unit nurses and their need for support: Explorative interviews. British Association of Critical Care Nurses, 19(4), 166-174. https://doi.org/10.1111/nicc.12020

De Vos, A. S., Strydom, H., Fouche, G. B., \& Delport, C. S. L. (2011). Research at Grassroots. For the social sciences and human service professions (4th ed.). Pretoria: Van Schaik.

Dhai, A., \& McQuoid- Mason, D. (2011). Bioethics, Human Rights and Health Law. Principles and Practice: Juta. Cape Town.

Edrees, H., \& Federico, F. (2015). Supporting Clinicians after Medical Error. British Medical Journal, https://doi.org./10.1136.bmj.h1982

Edrees, H., Connors, C., Paine, L., Norvell, M., Taylor, H., \& Wu, A.W. (2016). Implementing the RISE second victim support programme at the Johns Hopkins Hospital: A case study. BMJ Open, 6(9), e011708. https://doi.org/10.1136/bmjopen-2016-011708

Ferrús, L., Silvestre, C., Olivera, G., \& Mira, J. J. (2016). Qualitative study about the experiences of colleagues of health professionals involved in an adverse event. Journal of Patient Safety. https://doi.org/10.1097/PTS.0000000000000309

Gray, J., Grove, S. K., \& Sutherland, S. (2017). Burns and Grove's the practice of nursing research: appraisal, synthesis, and generation of evidence (8th ed.). St Louis, Missouri: Elsevier Mosby.

Grissinger, M. (2014). Too many abandon the "second victims of medical errors." Pharmacy \& Therapeutics. Institute for Safe Medication Practices, 39(9).

Jones, J. H., \& Treiber, L. A. (2012). When Nurses become the "second victim. Nursing Forum, 47(4).

Kirby, R. (2014). Supporting the "Second Victim" after a Medical Error. Trends in Urology \& Men's Health. John Wiley \& Sons.

Leferink, E. H. M., Bos, A., Heringa, M. P., van Rensen, E. L. J., Dorien, L. M., \& Zwart, D. L. M. (2018). The need and availability of support systems for physicians involved in a serious adverse event. Journal of Hospital Administration, 7(2). https://doi.org/10.5430/jha.v7n2p23

Lewis, E. J., Baernholdt, M., \& Hamric, A. B. (2013). Nurses Experience of Medical Errors: An Integrative Literature Review: Journal of Nursing Care Quality, 28(2), 153-161.

Lincoln, Y.S., \& Guba, E.G. (1985). Naturalistic Inquiry (pp. 294-326). London: Sage.

Mira, J. J., Lorenzo, S., Carrillo, I., Ferrús, L., Silvestre, C., \& Astier, P. (2017). Lessons learned for reducing the negative impact of adverse events on patients, health professionals and healthcare organisations. Int J Qual Health Care, 00.

Mohan, K., \& Gomathi, S. (2015). The effects of Job Rotation Practices on Employee Development: An Empirical Study on Nurses in the hospital of Vellore District. Mediterranean Journal of Social Sciences, (1). https://doi.org/10.5901/mjss.2015v6n1.209

Mohsenpour, M., Hosseini, M., Abbaszadeh, A., Shahboulaghi, F. M., \& Khankeh, H. (2016). Iranian Nurses' Experiences of Being a "Wrongdoer". A Phenomenological Study. Research Article.

Muller, M., Bezuidenhout, M., \& Jooste, K. (2011). Healthcare Service Management (2nd ed.). Cape Town: Juta.

Ngako, J. K., Van Rensburg, E. S. J., \& Mataboge, S. M. L. (2012). 'Psychiatric Nurse Practitioner' Experiences of Working with Mental Health Care Users presenting with Acute Symptoms. Curationis, 35(1), E1-E9. https://doi.org/10.4102/curationis.v35i1.44

Partanen, A. (2014). Nurse Managers' Experiences of Goal Oriented Job Rotation (Masters' Thesis, JAMK University of Applied Sciences, Finland).

Pelt, J. L., \& Faldmo, L. P. (2012). Disclosure and Discussion of Adverse Events. Committee Opinion. American College of Obstetricians \& Gynecologists, 119, 686.

Polit, D. F., \& Beck, C. T. (2018). Essentials of Nursing Research (9th ed.). Philadelphia, PA: Wolters Kluwer. 
Pyo, J., Han, Y. J., \& Ock, M. (2018). A qualitative case study regarding bereaved family's experience due to medical accident: focusing on participants in medical disputes. Korea J Couns, 19(5), 1-25.

Rafter, N., Hickey, A., Codell, S., Conroy, R., O’Connor, P., Vaughan, D., \& Williams, D. (2015). Adverse Events in Healthcare: Learning from Mistakes. Quarterly Journal of Medicine, 108(4). https://doi.org/10.1093/qjmed/hcu145

Scott, S. D., Hirschinger, L. E., Cox, K. R., McCoig, M., Brandt, J., \& Hall, L. W. (2009). The Natural History of Recovery for the Healthcare Provider "second victim" after Adverse Patient Events. Qual Saf Health Care; 18(5), 325-330. https://doi.org/10.1136/qshc.2009.032870.

Seys, D., Wu, A. W., Van Gerven, E., Vleugels, A., Euwema, M., \& Panella, M. (2013). Health care professionals as second victims after adverse events: A systematic review. Eval Health Prof, 36(2), 135-162. https://doi.org/10.1177/0163278712458918

Sobekwa, Z. C., \& Arunachallam, S. (2015). Experiences of Nurses Caring for Mental Health Care Users in an Acute Admission Unit at a Psychiatric Hospital in the Western Cape Province. Curationis, 38(2). 1509.

Sodeify, R., Vanaki, Z., \& Mohammadi, E. (2013). Nurses' Experiences of Perceived Support and their Contributing Factors: A qualitative content analysis. Iranian Journal of Nursing and Midwifery Research, 18(3), 191-197.

South African Department of Health. (2005). South African Nursing Act 33 of 2005. Pretoria: Government Printers.

Swift, S. (2013). "It's a Little Scar". A Phenomenological Study of Nurses' Responses Following Direct Involvement in a Nursing Error. PhD Dissertation. University of Tennessee.

Ullström, S., Sachs M. A., Hansson, J., Ovretveit, J., \& Brommels, M. (2014). Suffering in silence: A Qualitative Study of Second Victims of Adverse Events. British Medical Journal Quality \& Safety, 23(4), 325-331. https://doi.org/10.1136/bmjqs-2013-002035

Vanhaecht, K., Seys, D., Schouten, L., Bruyneel, L., Coeckelberghs, E., Panella, M., \& Zeeman, G. (2019). Duration of Second Victim Symptoms in the Aftermath of a Patient Safety Incident and Association with the Level of Patient Harm: A Cross-Sectional Study in the Netherlands. British Medical Journal Open, 9, e029923. https://doi.org/10.1136/bmjopen-2019-029923

\section{Copyrights}

Copyright for this article is retained by the author(s), with first publication rights granted to the journal.

This is an open-access article distributed under the terms and conditions of the Creative Commons Attribution license (http://creativecommons.org/licenses/by/4.0/). 